\title{
Enzymatic pH control for biomimetic deposition of calcium phosphate coatings
}

Citation for published version (APA):

Nijhuis, A. W. G., Nejadnik, M. R., Nudelman, F., Walboomers, X. F., te Riet, J., Habibovic, P., Birgani, Z. T., Li Yubao, Bomans, P. H. H., Jansen, J. A., Sommerdijk, N. A. J. M., \& Leeuwenburgh, S. C. G. (2014). Enzymatic $\mathrm{pH}$ control for biomimetic deposition of calcium phosphate coatings. Acta Biomaterialia, 10(2), 931-939. https://doi.org/10.1016/j.actbio.2013.09.036

Document status and date:

Published: 01/02/2014

DOI:

10.1016/j.actbio.2013.09.036

Document Version:

Publisher's PDF, also known as Version of record

Document license:

Taverne

Please check the document version of this publication:

- A submitted manuscript is the version of the article upon submission and before peer-review. There can be important differences between the submitted version and the official published version of record.

People interested in the research are advised to contact the author for the final version of the publication, or visit the DOI to the publisher's website.

- The final author version and the galley proof are versions of the publication after peer review.

- The final published version features the final layout of the paper including the volume, issue and page numbers.

Link to publication

\footnotetext{
General rights rights.

- You may freely distribute the URL identifying the publication in the public portal. please follow below link for the End User Agreement:

www.umlib.nl/taverne-license

Take down policy

If you believe that this document breaches copyright please contact us at:

repository@maastrichtuniversity.nl

providing details and we will investigate your claim.
}

Copyright and moral rights for the publications made accessible in the public portal are retained by the authors and/or other copyright owners and it is a condition of accessing publications that users recognise and abide by the legal requirements associated with these

- Users may download and print one copy of any publication from the public portal for the purpose of private study or research.

- You may not further distribute the material or use it for any profit-making activity or commercial gain

If the publication is distributed under the terms of Article $25 \mathrm{fa}$ of the Dutch Copyright Act, indicated by the "Taverne" license above, 


\title{
Enzymatic pH control for biomimetic deposition of calcium phosphate coatings
}

\author{
Arnold W.G. Nijhuis ${ }^{\mathrm{a}, 1}$, M. Reza Nejadnik ${ }^{\mathrm{a}, 1}$, Fabio Nudelman ${ }^{\mathrm{b}}$, X. Frank Walboomers ${ }^{\mathrm{a}}$, Joost te Riet ${ }^{\mathrm{c}}$, \\ Pamela Habibovic ${ }^{\mathrm{d}}$, Zeinab Tahmasebi Birgani ${ }^{\mathrm{d}}$, Li Yubao ${ }^{\mathrm{e}}$, Paul H.H. Bomans ${ }^{\mathrm{b}}$, John A. Jansen ${ }^{\mathrm{a}}$, \\ Nico A.J.M. Sommerdijk ${ }^{\mathrm{b}}$, Sander C.G. Leeuwenburgh ${ }^{\mathrm{a}, *}$ \\ ${ }^{a}$ Department of Biomaterials, Radboud University Medical Center, Philips van Leydenlaan 25, 6525 EX Nijmegen, The Netherlands \\ ${ }^{\mathrm{b}}$ Laboratory of Materials and Interface Chemistry and Soft Matter CryoTEM Unit, Eindhoven University of Technology, PO Box 513, 5600 MB Eindhoven, The Netherlands \\ ${ }^{\mathrm{c}}$ Department of Tumor Immunology, Nijmegen Centre for Molecular Life Sciences, Radboud University Medical Center, Geert Grooteplein 28 , 6525 GA Nijmegen, The Netherlands \\ ${ }^{\mathrm{d}}$ Department of Tissue Regeneration, MIRA Institute for Biomedical Technology and Technical Medicine, Faculty of Science and Technology, University of Twente, PO Box 217 \\ 7500AE Enschede, The Netherlands \\ ${ }^{\mathrm{e}}$ Research Center for Nano-Biomaterials, Analytical and Testing Center, Sichuan University, 610064 Chengdu, People's Republic of China
}

\section{A R T I C L E I N F O}

\section{Article history:}

Received 17 May 2013

Received in revised form 6 August 2013

Accepted 26 September 2013

Available online 3 October 2013

\section{Keywords:}

Calcification

Pre-nucleation clusters

Patterned surfaces

Hydroxyapatite

Calcium phosphate coating

\begin{abstract}
A B S T R A C T
The current study examines the enzymatic decomposition of urea into carbon dioxide and ammonia as a means to increase the $\mathrm{pH}$ during biomimetic deposition of calcium phospate (CaP) onto implant surfaces. The kinetics of the enzymatically induced $\mathrm{pH}$ increase were studied by monitoring $\mathrm{pH}$, calcium concentration and conductivity of the aqueous solutions as a function of time, urease concentration and initial concentrations of calcium and phosphate ions. Cryogenic transmission electron microscopy was used to study the process of homogeneous CaP precipitation in solution, whereas CaP deposition on conventional acid-etched titanium and micropatterned polystyrene (PS) surfaces was studied using scanning electron microscopy. The data presented in this study confirm that the substrate-enzyme combination urea-urease offers strong control over the rate of $\mathrm{pH}$ increase by varying the concentrations of precursor salts and urease. Formation of biomimetic CaP coatings was shown to proceed via formation of ionic polymeric assemblies of prenucleation complexes. The process of deposition and corresponding coating morphology was strongly dependent on the concentration of calcium, phosphate and urease. Finally, it was shown that the substrate-enzyme combination urea-urease allowed for spatial distribution of CaP crystals along the grooves of micropatterned PS surfaces at low concentrations of calcium, phosphate and urease, stressing the sensitivity of the presented method.
\end{abstract}

(c) 2013 Acta Materialia Inc. Published by Elsevier Ltd. All rights reserved.

\section{Introduction}

Bone tissue owes its exceptional functional properties to its unique hierarchical and spatially organized nanostructure. This nanostructure is formed by means of a highly controlled mineralization process that results in the embedding and ordered alignment of nanosized calcium phosphate $(\mathrm{CaP})$ platelets within the interstices of collagen fibrils [1]. In view of the beneficial osteoconductive properties of $\mathrm{CaP}$ ceramics, a plethora of physical and wetchemical techniques have been developed to deposit CaP onto orthopedic and oral implant surfaces. Conventional physical coating techniques (e.g. plasma-spraying or physical vapor deposition) or wet-chemical deposition methods (e.g. electrochemical deposition) typically produce dense coatings that cover the implant

\footnotetext{
* Corresponding author.

E-mail address: Sander.Leeuwenburgh@radboudumc.nl (S.C.G. Leeuwenburgh).

1 These authors contributed equally to this work.
}

surface homogeneously. Although physical deposition techniques are more frequently commercialized than wet-chemical deposition techniques, their harsh process conditions (e.g. extremely high temperatures or low pressures) impose severe limitations to upgrading the biological efficacy of these coatings by co-deposition of biomolecules or spatially organized deposition. In that respect, wet-chemical deposition of CaP coatings from solutions at physiological conditions $\left(37^{\circ} \mathrm{C}, \mathrm{pH} 7.4\right.$ and appropriate electrolyte concentrations) has attracted considerable interest over the past two decades. These so-called biomimetic coatings are based on the work of Kokubo on simulated body fluid (SBF) and have been explored extensively [2-10]. In the 1990s, these SBF solutions were used in view of their metastable nature with respect to CaP deposition; however, deposition times of up to several weeks were necessary to prepare sufficiently thick CaP coatings. Therefore, accelerated versions of the biomimetic coating process have been developed which exploit the fact that the solubility of CaP increases with decreasing $\mathrm{pH}$ [11]. The most extensively studied 
approaches rely on decreasing the $\mathrm{pH}$ by dissolving $\mathrm{CO}_{2}$ gas or sodium bicarbonate salt, thereby allowing for dissolution of higher concentrations of calcium and phosphate precursors. Subsequent release of $\mathrm{CO}_{2}$ results in increasing $\mathrm{pH}$ of the solution and corresponding deposition of $\mathrm{CaP}$ onto implants within days rather than weeks $[12,13]$. Although the process is accelerated significantly compared to the conventional use of SBF solutions, the control over release of $\mathrm{CO}_{2}$ is strongly dependent on parameters such as stirring speed, reactor geometry and solution volume. As a result, control over the rate of $\mathrm{pH}$ increase is limited, which severely complicates control over nucleation and growth of CaP crystals as well as upscaling and commercialization of the biomimetic coating procedure.

In view of their high specificity, enzymes may offer improved control over the $\mathrm{pH}$ for the biomimetic coating process $[14,15]$. Herein, we propose the use of the enzyme urease as this enzyme offers tight control over the gradual increase of $\mathrm{pH}$ in aqueous solutions by catalyzing the hydrolysis of urea into $\mathrm{CO}_{2}$ and basic ammonia. The substrate-enzyme combination urea-urease was previously investigated for the precipitation of various ceramic materials including CaP powders [14-18]. In other approaches, urease was immobilized onto polymeric substrates such as polydivinylbenzene, silk cloth or poly-L-lactic acid in order to aid the formation of CaP layers on these substrates [19-21]. The use of urea and urease for deposition of CaP coatings onto implants was reported before, but important details on the kinetics of $\mathrm{pH}$ increase as well as the relationship between process parameters and the resulting coating properties are largely lacking. As a consequence, the substrate-enzyme combination urea-urease has not yet realized its full potential.

Therefore, we have systematically studied the characteristics of enzymatic $\mathrm{pH}$ control for deposition of CaP onto implant surfaces using a threefold approach. First, the kinetics of the enzymatically induced $\mathrm{pH}$ increase were studied by monitoring $\mathrm{pH}$, calcium concentration and electrical conductivity of the aqueous solutions as a function of time, urease concentration and initial concentrations of calcium and phosphate ions. Second, cryogenic transmission electron microscopy (cryoTEM) was used to study the process of CaP precipitation in solution by applying plunge-freeze vitrification to ensure the close-to-native preservation of the molecular structures. Finally, deposition of CaP was studied on conventional acid-etched titanium (Ti) implant surfaces using scanning electron microscopy (SEM); micropatterned polystyrene (PS) surfaces were also used as substrate for CaP deposition, in order to study the effect of micropatterning on CaP deposition.

\section{Materials and methods}

\subsection{Materials}

Urease (type III from Jackbeans, U1500-20kU, Sigma-Aldrich), $\mathrm{Na}_{2} \mathrm{HPO}_{4}$ (Merck), $\mathrm{NaCl}$ (Merck), $\mathrm{CaCl}_{2}$ (Baker), urea (Invitrogen) and PS (Acros) were of analytical grade and used as received. Commercially obtained pure Ti discs $(12 \mathrm{~mm}$ diameter, $1.5 \mathrm{~mm}$ thick) were acid-etched prior to use for $90 \mathrm{~s}$ in a mixture of $\mathrm{HCl}: \mathrm{H}_{2} \mathrm{SO}_{4}: \mathrm{H}_{2} \mathrm{O} 1: 1: 1$ (by volume) at $95^{\circ} \mathrm{C}$ to obtain a surface roughness suitable for coating attachment. Grooved PS films were prepared as described before [22]. Briefly, $0.5 \mathrm{~g}$ PS dissolved in $3 \mathrm{ml}$ chloroform was cast onto a 3 in. silicon wafer mold (with $1 \mu \mathrm{m}$ grooves generated using electron beam lithography). The chloroform was evaporated to yield a PS film [22]. Atomic force microscopy (AFM, Nanoscope IIIa, Bruker, Santa Barbara, CA, USA) with Nanoscope Analysis software (version 1.30, Bruker) was used to measure the root mean squared surface roughness $\left(R_{\mathrm{q}}\right)$ values of the grooves and ridges. Solutions containing calcium and phosphate ions (see Table 1 ) were prepared by dissolving $\mathrm{CaCl}_{2}, \mathrm{Na}_{2} \mathrm{HPO}_{4}, \mathrm{NaCl}$ and urea as follows. First, $\mathrm{Na}_{2} \mathrm{HPO}_{4}$ and $\mathrm{NaCl}$ were dissolved in $80 \%$ of the required amount of deionized water, followed by the addition of $1 \mathrm{M} \mathrm{HCl}$ to adjust the $\mathrm{pH}$ to 6.0 ; subsequently $\mathrm{CaCl}_{2}$ was added and the solution was adjusted to the final volume. The solutions were filtered through a surfactant-free cellulose acetate filter unit (pore size $0.2 \mu \mathrm{m}$ ) and stored at $4-6{ }^{\circ} \mathrm{C}$. Prior to each experiment, urea was added, the $\mathrm{pH}$ was adjusted to 6.0 and the solutions were filtered for the second time. To start the experiments, the solution was heated to $37{ }^{\circ} \mathrm{C}$ and urease was added to initiate the decomposition of urea and the corresponding $\mathrm{pH}$ increase.

\subsection{Analysis of $\mathrm{pH}$, calcium concentration and conductivity}

All reactions were performed at a temperature of $37^{\circ} \mathrm{C}$. The urea concentration was fixed at $100 \mathrm{mM}$ since at this concentration the conversion rate was reported to be independent of substrate concentration [23]. To obtain more insight into the kinetics of $\mathrm{pH}$ increase using the substrate-enzyme combination urea-urease, $\mathrm{pH}$ was measured as a function of time as well as composition of the precursor solutions (i.e. concentration of urease, calcium and phosphate). To this end, $0.2 \mathrm{U} \mathrm{ml}^{-1}$ urease was added to solutions containing concentrations of calcium and phosphate that were either equal (1CaP) or increased 3- or 5-fold (3CaP or $5 \mathrm{CaP}$, respectively) relative to SBF (see Table 1 ) [3]. Moreover, the effect of different urease concentrations $\left(0.04,0.2\right.$ and $\left.1 \mathrm{U} \mathrm{ml}^{-1}\right)$ on the kinetics of $\mathrm{pH}$ increase was investigated for a $5 \mathrm{CaP}$ solution. In these experiments $250 \mathrm{ml}$ of calcium- and phosphate-containing solution was placed in a PS container while a pH electrode (Meterlab PHM210 calibrated with IUPAC buffers, S11M002, S11M004, S11M007 from Radiometer Analytical) was present in the solution to record the $\mathrm{pH}$. Conductivity was measured using the same experimental set-up with the additional presence of a WTW cond $315 \mathrm{i}$ conductivity meter. In this experiment, the solution was $\mathrm{NaCl}$-free $(5 \mathrm{CaP}-0 \mathrm{NaCl})$ and contained $0.2 \mathrm{U} \mathrm{ml}^{-1}$ urease, while the starting $\mathrm{pH}$ was 5.0 since the $5 \mathrm{CaP}-0 \mathrm{NaCl}$ solution was not stable at $\mathrm{pH}$ 6.0. Simultaneous measurements of the calcium concentration and $\mathrm{pH}$ were performed using a modified set-up in which $100 \mathrm{ml}$ of calcium- and phosphate-containing solution (3CaP) containing $0.5 \mathrm{U} \mathrm{ml}^{-1}$ urease was placed in a glass container. A calcium electrode, $\mathrm{pH}$ electrode, a temperature sensor and a PS substrate were present in the calcium- and phosphate-containing solution. The calcium-sensitive electrode (Ca-ISE, Metrohm Ltd., Switzerland) and a pH glass electrode (LL Micro glass electrode, Metrohm) were connected to a Titrando TM titration device (Metrohm) and analyzed online using TiamoTM software (Metrohm). The $\mathrm{pH}$ electrode was calibrated using standard buffers at $\mathrm{pH} 4.0$, 7.0 and 9.0 (Metrohm, Nos. 6.2307.100, 6.2307.110, 6.2307.120). The Ca-ISE was calibrated by titrating the $10 \mathrm{mM}$ calcium stock against $25 \mathrm{ml}$ Tris-buffered saline ( $\mathrm{pH} \mathrm{7.4)}$ at room temperature with an addition rate of $0.1 \mathrm{ml} \mathrm{min}^{-1}$ using a DosinoTM dosing device and measuring the signal (in $\mathrm{mV}$ ) as a function of the calcium concentration present. During the calibration titration, the $\mathrm{pH}$ was kept constant at 6 . In addition, we performed a second calibration of the Ca-ISE electrode where the concentration of calcium ions in

Table 1

Composition of the different solutions used in the various experiments.

\begin{tabular}{llcc}
\hline Solution & $\mathrm{Na}_{2} \mathrm{HPO}_{4}(\mathrm{mM})$ & $\mathrm{CaCl}_{2}(\mathrm{mM})$ & $\mathrm{NaCl}(\mathrm{mM})$ \\
\hline $5 \mathrm{CaP}$ & 5 & 12.5 & 733 \\
$3 \mathrm{CaP}$ & 3 & 7.5 & 440 \\
$1 \mathrm{CaP}$ & 1 & 2.5 & 147 \\
$5 \mathrm{CaP}-0 \mathrm{NaCl}$ & 5 & 12.5 & 0 \\
\hline
\end{tabular}


SBF was kept constant by preparing the solution without phosphate ions, while the $\mathrm{pH}$ was increased using the ureasecatalyzed decomposition of urea. It was observed that the measured concentration of calcium varied linearly with the increase in $\mathrm{pH}$. From this reaction we then calculated a factor that was subtracted from the experimental calcium concentration curve.

\subsection{Analysis of CaP formation using cryoTEM}

CryoTEM analysis was employed to investigate if pre-nucleation complexes could be observed in our system with variable $\mathrm{pH}$ similar to the previously reported presence of these complexes in metastable solutions of constant $\mathrm{pH}$ [24]. We selected the 3CaP solution with $0.5 \mathrm{U} \mathrm{ml}^{-1}$ urease for this cryoTEM analysis in view of the faster rates of nucleation and deposition, since a pilot study showed that that this experimental condition would allow for continuous collection of samples prior, during and after the $\mathrm{pH}$ drop within $8 \mathrm{~h}$. $0.5 \mathrm{U} \mathrm{ml}^{-1}$ urease was added to a 3CaP solution ( $100 \mathrm{ml}$ solution in a glass container containing a $\mathrm{pH}$ electrode, a calcium electrode, a temperature sensor and a grooved PS substrate) and at various time points, samples for cryoTEM were obtained using a vitrification robot (FEI Vitrobot Mark III). CryoTEM grids (R2/2 Quantifoil Jena grids) were purchased from Quantifoil Micro Tools $\mathrm{GmbH}$. Prior to the vitrification procedure these grids were surface plasma treated using a Cressington 208 carbon coater. The cryoTEM characterizations were performed on a CryoTitan (FEI) equipped with a field emission gun operating at $300 \mathrm{kV}$ and a postcolumn Gatan energy filter. Images were recorded using a $2 \mathrm{k} \times 2 \mathrm{k}$ Gatan CCD camera. Selected-area electron diffraction (SAED) was used to determine the crystal phase of observed aggregates. Since cryoTEM in combination with SAED analysis was not suitable to provide evidence on the crystallinity of CaP during the final stages of the coating process, we used X-ray diffraction (XRD) analysis to confirm the crystallinity of the precipitates produced. Therefore, the precipitated material was collected by centrifugation, washed three times with water and dried in air $\left(37^{\circ} \mathrm{C}\right)$. XRD patterns of this powder were recorded on a Panalytical XRD using a $\mathrm{Cu} K_{\alpha}$ radiation source, while scanning the detector from $4^{\circ}$ to $36^{\circ} 2 \theta$ in steps of $0.02^{\circ}$ at a sampling time of $2 \mathrm{~s}$ per step.

\subsection{Analysis of CaP depositions}

In order to study the feasibility of using the substrate-enzyme combination urease-urea for the deposition of $\mathrm{CaP}, \mathrm{Ti}$ substrates and PS substrates were incubated in the solutions in a vertical position. The Ti substrates were incubated in $2 \mathrm{ml}$ of $5 \mathrm{CaP}$ with 0.04 , 0.2 or $1 \mathrm{U} \mathrm{ml}^{-1}$ urease in PS containers, whereas the PS substrates were incubated in $100 \mathrm{ml} 1 \mathrm{CaP}$ or $3 \mathrm{CaP}$ with 0.1 . 0.2 or $0.5 \mathrm{U} \mathrm{ml}^{-1}$ urease. At various time points during the biomimetic coating process, Ti substrates were collected or small sections of the microgrooved PS film were cut, washed extensively with water, lyophilized and analyzed. SEM and cryoTEM characterizations were performed simultaneously, i.e. on samples taken from 3CaP solutions containing $0.5 \mathrm{U} \mathrm{ml}^{-1}$ urease. In addition, various experimental runs were performed at lower supersaturation $(1 \mathrm{CaP})$ and urease concentrations (ranging between 0.1 and $0.2 \mathrm{U} \mathrm{ml}^{-1}$ ). SEM (JEOL 6340F) was performed after covering the $\mathrm{CaP}$-coated $\mathrm{Ti}$ and micropatterned PS samples with a conductive thin film of gold. Elemental analysis was carried out using a Philips XL30 scanning electron microscope (Eindhoven, the Netherlands) equipped with an energy dispersive spectrometer (EDS, AMETEK Materials Analysis Division, Mahwah, NJ, USA). To improve the surface conductivity of the samples, a thin gold layer was deposited on the samples using a standard sputtering instrument (Cressington 108A, Watford, UK). EDS analysis provided information on the distribution of elements of interest ( $\mathrm{Ca}$ and $\mathrm{P}$ ) in the analyzed area. XRD patterns of $\mathrm{CaP}$ coated samples were recorded at a fixed angle of incidence of $2.5^{\circ}$, while scanning the detector from $4^{\circ}$ to $36^{\circ} 2 \theta$ in steps of $0.02^{\circ}$ at a sampling time of $2 \mathrm{~s}$ per step. Fourier transform infrared spectroscopy (FTIR, $500-1750 \mathrm{~cm}^{-1}$ ) of CaP-coated substrates was performed using a Spectrum One instrument (Perkin-Elmer) in reflection mode.

\section{Results}

\subsection{Analysis of $\mathrm{pH}$, calcium concentration and conductivity}

All CaP precursor solutions (Table 1) were stable at $\mathrm{pH} 6.0$ (defined by the absence of visible precipitation or changes in $\mathrm{pH}$ for at least $1 \mathrm{month}$ ), except for $5 \mathrm{CaP}-\mathrm{ONaCl}$ which was stable at $\mathrm{pH}$ 5.0. We monitored the $\mathrm{pH}$ increase of these solutions upon the addition of urease. In Fig. $1 \mathrm{~A}$ the $\mathrm{pH}$ is depicted as a function of time for three different precursor salt concentrations, while Fig. 1B shows $\mathrm{pH}$ profiles as a function of urease concentration. Initially, $\mathrm{pH}$ values increased with time followed by a drop of about 0.3-0.5 pH units, the time point and duration of which decreased with increasing precursor salt and increasing urease concentration. The initial slopes of the increase in $\mathrm{pH}$ decreased with increasing precursor salt concentration $\left(6.7,3.4\right.$ and $2.4 \mathrm{pH}$ units $\mathrm{h}^{-1}$ for $1 \mathrm{CaP}, 3 \mathrm{CaP}$ and $5 \mathrm{CaP}$, respectively), whereas the slopes increased with increasing urease concentration $(10.2,2.4$ and $0.47 \mathrm{pH}$ units $\mathrm{h}^{-1}$ for $1,0.2$ and $0.04 \mathrm{U} \mathrm{ml}^{-1}$ urease, respectively). Simultaneous measurements of $\mathrm{pH}$ and conductivity (Fig. 2A) showed that the electrical conductivity of the precursor solutions increased in time
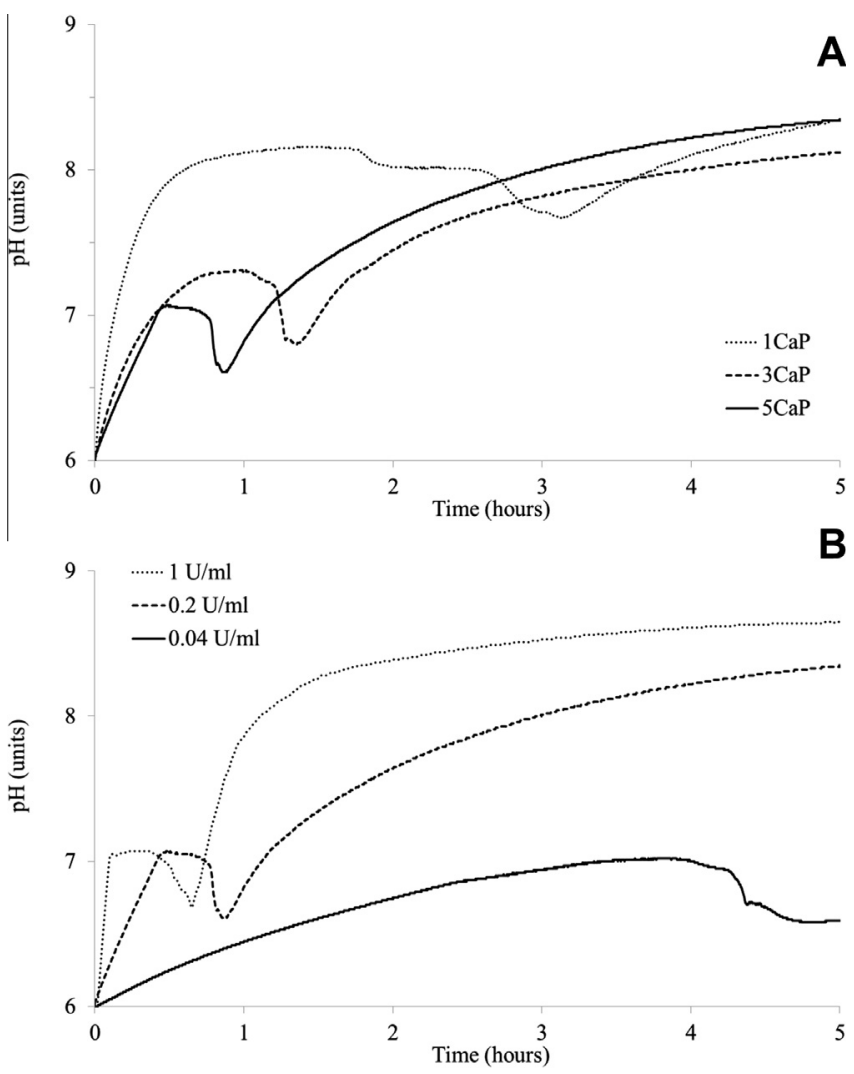

Fig. 1. (A) Effect of calcium and phosphate concentrations (5CaP, 3CaP and $1 \mathrm{CaP}$ solutions) on $\mathrm{pH}$ upon addition of $0.2 \mathrm{U} \mathrm{ml}^{-1}$ urease $(250 \mathrm{ml}$ solution in a PS container with a pH electrode present). (B) Effect of urease concentration on $\mathrm{pH}$ at a fixed (5CaP solution) concentration of calcium and phosphate ions ( $250 \mathrm{ml}$ solution in a PS container with a $\mathrm{pH}$ electrode present). 

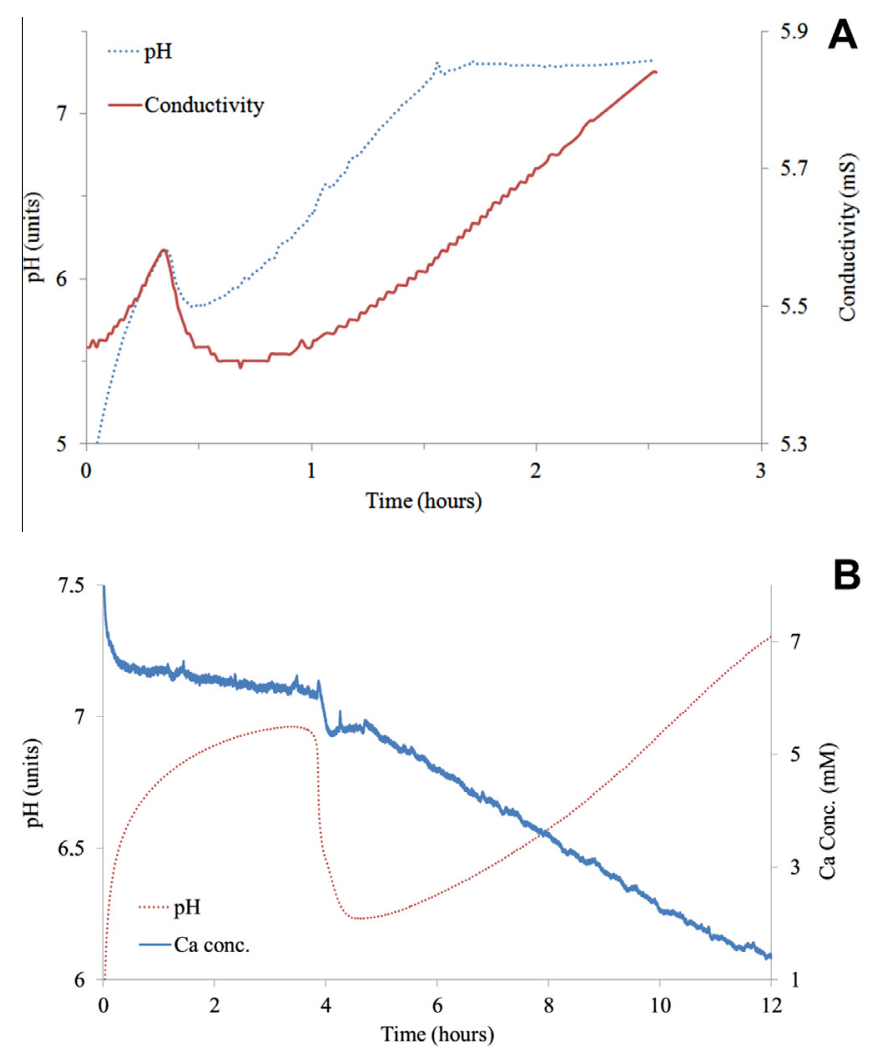

Fig. 2. (A) $\mathrm{pH}$ and electrical conductivity of $5 \mathrm{CaP}-0 \mathrm{NaCl}$ solution upon addition of $0.2 \mathrm{U} \mathrm{ml}^{-1}$ urease $(250 \mathrm{ml}$ solution in a PS container with a $\mathrm{pH}$ electrode and conductivity meter present). (B) Simultaneous measurement $\mathrm{pH}$ and calcium ion concentration in a $3 \mathrm{CaP}$ solution after addition of $0.5 \mathrm{U} \mathrm{ml}^{-1}$ urease $(100 \mathrm{ml}$ solution in a glass container with a $\mathrm{pH}$ electrode, calcium electrode, temperature sensor and PS substrate present).

except for a drop which coincided with the observed drop in $\mathrm{pH}$. Fig. 2B shows the amount of free calcium in the precursor solution as measured over time using a calcium-selective electrode. After an initial steep decrease, the amount of calcium slowly decreased linearly until a slight drop coinciding with the $\mathrm{pH}$ drop, clearly marking the nucleation of the first solid phase, after which the calcium concentration decreased linearly again but at a faster rate.

\subsection{Analysis of CaP formation using cryoTEM}

Fig. 3 shows cryoTEM images of the samples which were vitrified at the time points as indicated in the $\mathrm{pH}$ profile of the reaction $3 \mathrm{CaP}$ with $0.5 \mathrm{U} \mathrm{ml}^{-1}$ urease depicted in Fig. 3A. Immediately after addition of urease, cryoTEM images showed the formation of a branched polymeric network of pre-nucleation complexes similar to those recently reported by Habraken et al. (Fig. 3B) [24]. With increasing time and $\mathrm{pH}$ these gradually densify and coarsen-in agreement with previous observations in the early stages of precipitation from SBF (Fig. 3C) developing in extended and more defined chains of assembled complexes (Fig. 3D) [25]. During nucleation, as signified by the $\mathrm{pH}$ drop, homogeneous nucleation was observed in solution during which the polymeric chains of complexes collapsed into densely packed aggregates which almost exceeded the size of the micrographs (Fig. 3E). Corresponding SAED spectroscopy (Fig. 3E insert) revealed that these dense aggregates were amorphous. The XRD pattern (Fig. 4) of the precipitated material that was collected from the solution after $20 \mathrm{~h}$ revealed reflection peaks for apatitic CaP at $2 \theta=25.7^{\circ}, 31.6^{\circ}$ and $31.9^{\circ}$.
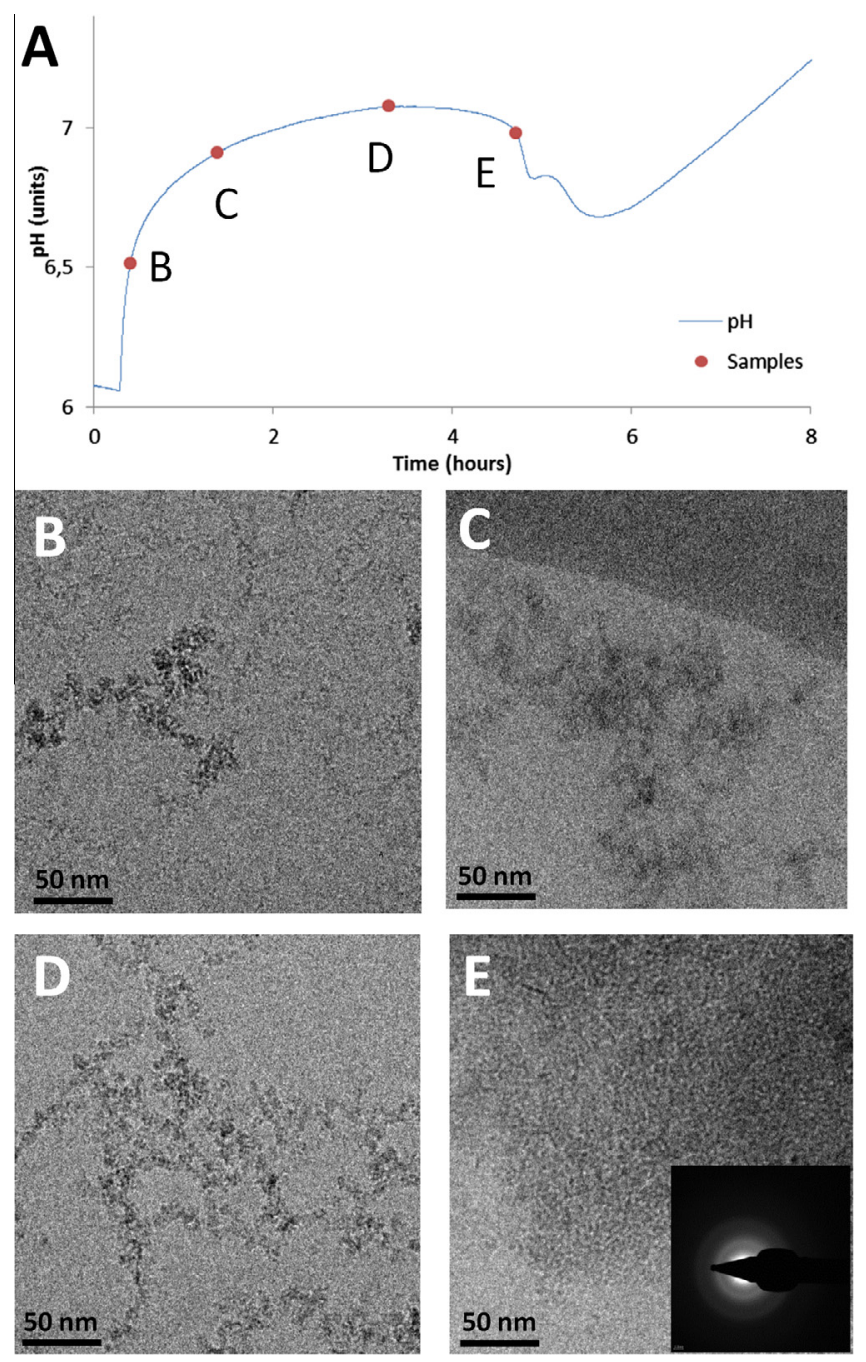

Fig. 3. Sampling times for cryoTEM (A) and cryoTEM images of vitrified samples from the 3CaP solution at $0.1 \mathrm{~h}(\mathrm{~B}), 1 \mathrm{~h}(\mathrm{C}), 3 \mathrm{~h}(\mathrm{D})$ and $4.4 \mathrm{~h}(\mathrm{E})$ after addition of $0.5 \mathrm{U} \mathrm{ml}^{-1}$ urease $(100 \mathrm{ml}$ solution in a glass container with a $\mathrm{pH}$ electrode, calcium electrode, temperature sensor and PS substrate present). Insert: SAED of the depicted densified aggregate.

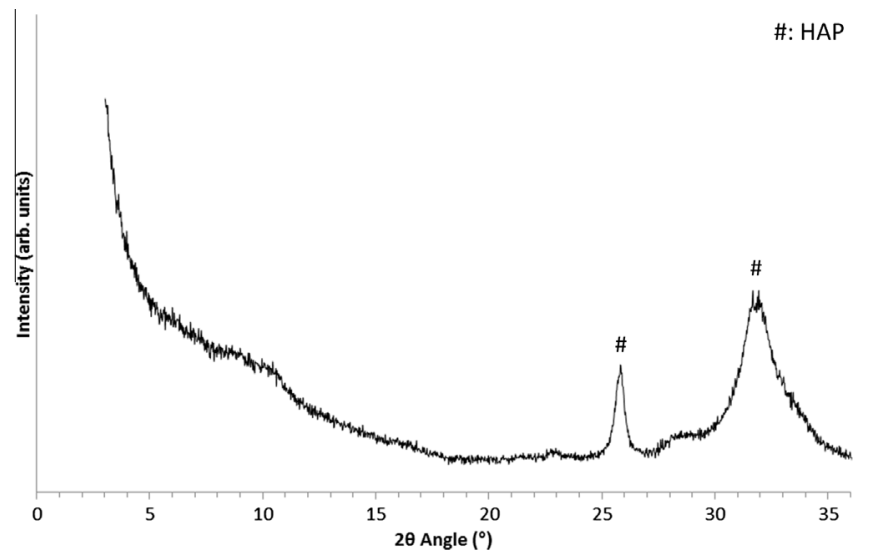

Fig. 4. XRD analysis of the precipitates formed at later stages $(20 \mathrm{~h})$ during the deposition using $3 \mathrm{CaP}$ and $0.5 \mathrm{U} \mathrm{ml}^{-1}$ urease $(100 \mathrm{ml}$ solution in a glass container with a temperature sensor present). 


\subsection{Analysis of CaP depositions}

SEM of CaP depositions onto Ti revealed that high concentrations of urease ( 1.0 and $0.2 \mathrm{U} \mathrm{ml}^{-1}$ ) resulted into homogeneous coverage of the substrate surface after $20 \mathrm{~h}$ (Fig. 5A,B and C,D, respectively), whereas at a lower urease concentration of $0.04 \mathrm{U} \mathrm{ml}^{-1}$ (Fig. 5E-F) the surface was not completely covered. Moreover, the size of the deposited CaP crystals increased with decreasing urease concentration. The amount of deposited $\mathrm{CaP}$ for the lowest urease concentration was not sufficient for FTIR analysis, but the FTIR spectra of thicker coatings prepared at urease concentrations of 0.2 and $1.0 \mathrm{U} \mathrm{ml}^{-1}$ displayed distinct absorption peaks at 863,913 and $1128 \mathrm{~cm}^{-1}$ characteristic for protonated $\mathrm{HPO}_{4}{ }^{2-}$ groups (Fig. 6A). The main absorption bands at 562, 602, 963 and $1014 \mathrm{~cm}^{-1}$ were characteristic of apatitic phosphate ions, while the absorption peak at $627 \mathrm{~cm}^{-1}$ confirmed the presence of hydroxyl groups. Coatings deposited at a high urease concentration (1.0 $\mathrm{U} \mathrm{ml}^{-1}$ ) also displayed carbonate absorption peaks (B-type) at 1422 and $1467 \mathrm{~cm}^{-1}$, indicating that a rapid increase in $\mathrm{pH}$ resulted in increased incorporation of carbonate into the apatite lattice. Corresponding XRD patterns (Fig. 6B) revealed sharp reflection peaks for apatitic CaP at $2 \theta=25.9^{\circ}, 31.5^{\circ}$ and $32.0^{\circ}$. The coating prepared with $0.04 \mathrm{U} \mathrm{ml}^{-1}$ revealed additional reflections at $4.5^{\circ}$ and $9.4^{\circ}$, which can be attributed to octacalcium phosphate (OCP), while the reflection at $15.9^{\circ}$ corresponded to OCP with a preferred $(-101)$ orientation [4,26,27]. XRD analysis revealed similar diffraction patterns for CaP depositions onto PS substrates even though the diffraction intensities were lower due to the lower thickness of CaP coatings on top of PS (data not shown).

Deposition of CaP onto microgrooved PS did not occur within $3 \mathrm{~h}$ after addition of urease to a $3 \mathrm{CaP}$ solution (Fig. 7B-D). The first deposits were observed at $4.25 \mathrm{~h}$ and these grew in size (Fig. 7E-I) until full coverage by flake-like crystals was reached (Fig. 7J). At lower supersaturation (1CaP) and rate of $\mathrm{pH}$ increase (urease concentration $0.2 \mathrm{U} \mathrm{ml}^{-1}$ ) (Fig. 8), on the other hand, formation of CaP depositions was already observed within $3 \mathrm{~h}$ after addition of urease (Fig. 8C), but these crystals did not grow in size with increasing soaking time. Instead, the density of the deposits significantly increased between 3 and $6 \mathrm{~h}$ after addition of urease (Fig. 8D-E), until the surface was fully covered with a dense CaP layer (Fig. 7F). At urease concentrations of 0.1-0.2 $\mathrm{U} \mathrm{ml}^{-1}$, CaP deposits were occasionally spatially distributed along the edge or on top of the grooves of the underlying micropatterned PS substrate as revealed by SEM analysis (Fig. 9A) and elemental mapping for calcium (Fig. 10A) and phosphorus (Fig. 10B). In more detail, this specific spatial distribution of the CaP deposits on the micropatterned PS substrates was observed on 4 out of 12 repetitions of identical experiments. AFM analysis (Fig. 9B) of the PS substrates showed that the ridges were rougher than the grooves.

\section{Discussion}

The current study has focused on enzymatic decomposition of urea into carbon dioxide and ammonia as a means to increase the $\mathrm{pH}$ during biomimetic deposition of CaP onto implant surfaces. It was shown that the substrate-enzyme combination urea-urease offers strong control over the rate of $\mathrm{pH}$ increase in solutions which are metastable with respect to CaP. It was shown that formation of biomimetic CaP coatings proceeds via the formation and gradual densification of branched polymeric assemblies of pre-nucleation complexes, which at the point of nucleation collapsed, leading to the homogeneous precipitation of micron-sized CaP aggregates throughout the solution and deposition of CaP coatings onto implant surfaces. The number density of the deposits and the corresponding coating morphology was strongly dependent on the concentration of calcium, phosphate and urease, resulting in the deposition of either micron-sized flake-like CaP crystals at high concentrations of calcium and phosphate and rate of $\mathrm{pH}$ increase vs. nano-sized crystals at low concentrations of calcium and phosphate and rate of $\mathrm{pH}$ increase. The substrate-enzyme combination urea-urease allowed for the spatial distribution of CaP crystals along the grooves of micropatterned PS surfaces at low concentrations of calcium, phosphate and urease, stressing the sensitivity of the method presented herein.

\subsection{Analysis of $\mathrm{pH}$, calcium concentration and conductivity}

Generally, the initial rate of $\mathrm{pH}$ increase was proportional to the urease concentration, stressing the robustness and versatility of enzymatic control of $\mathrm{pH}$ for biomimetic deposition of CaP. Rates of pH increase decreased with increasing precursor salt concentration, which can be attributed to the reduced buffering capacity of the solutions at lower phosphate concentrations. After the initial linear increase in $\mathrm{pH}$, a drop in $\mathrm{pH}$ was observed-accompanied by a drop in electrical conductivity and calcium concentrationreflecting the onset of homogeneous precipitation of $\mathrm{CaP}$, as evidenced by the sudden increase in the opacity of the solutions. Typically, this $\mathrm{pH}$ drop was biphasic, which might be caused by formation of amorphous precursor phases prior to the formation of crystalline precipitates [24,28,29]. Nevertheless, we observed differences (e.g. the increase in $\mathrm{pH}$ in Fig. 2B proceeded at slower rates than predicted based on Fig. 1) in the rates of $\mathrm{pH}$ increase depending on experimental conditions such as the presence of sensors and electrodes, the container (glass or PS) and/or the volume of the mineralizing solutions. Besides the effect of experimental conditions on the $\mathrm{pH}$ profile, these reproducibility issues might have been caused by differences in enzymatic activity of urease, since the enzymatic activity of urease was observed to decrease with $10 \%$ within 5 months (data not shown). This emphasizes that

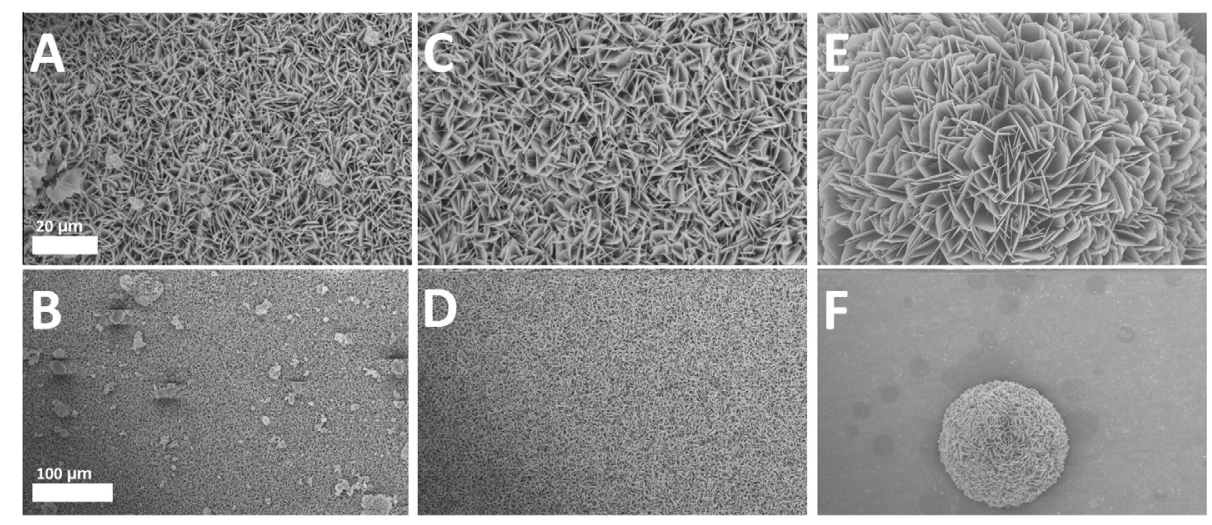

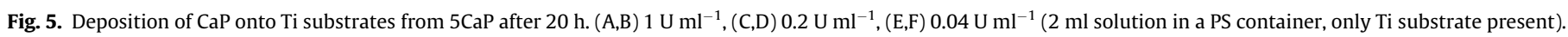




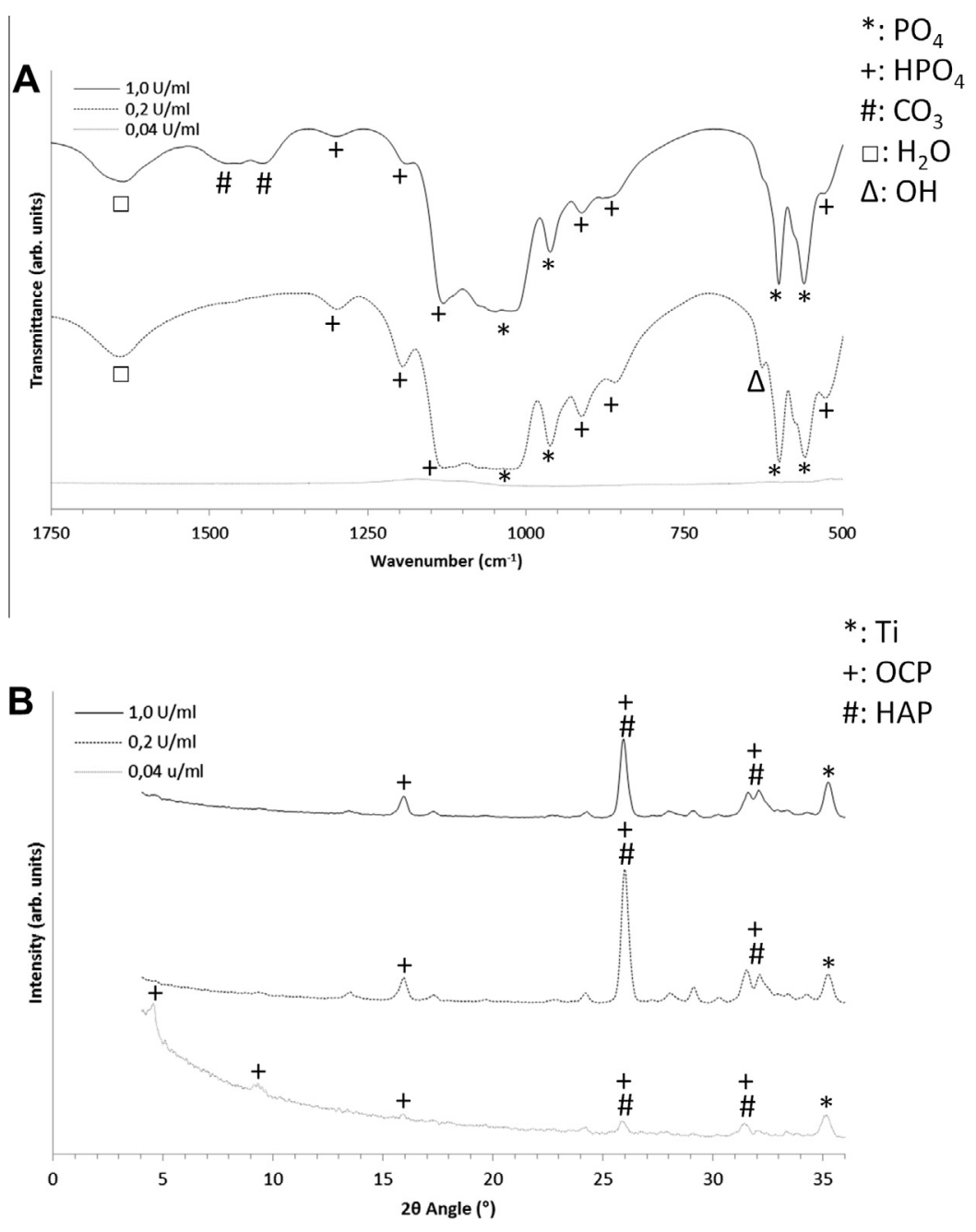

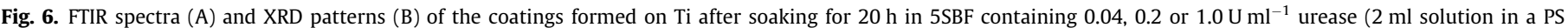
container, only Ti substrate present).

experimental conditions as well as urease activity should be standardized to improve reproducibility for the proposed method.

XRD analysis confirmed that the final crystalline deposits were mainly apatitic, while FTIR analysis showed that these apatites contained carbonate, hydroxyl and (protonated) phosphate ions, characteristic of calcium-deficient hydroxyapatite phosphate. The drop in $\mathrm{pH}$ can be attributed to the formation of hydroxyapatite according to the following reaction that accounts for the observed decrease in electrical conductivity by consumption of protons and calcium ions: $10 \mathrm{Ca}^{2+}+6 \mathrm{PO}_{4}^{3-}+2 \mathrm{OH}^{-} \Longleftrightarrow \mathrm{Ca}_{1} 0\left(\mathrm{PO}_{4}\right)_{6}(\mathrm{OH})_{2}$ [12].

Increased concentration of calcium and phosphate precursor salts resulted into homogeneous precipitation at lower $\mathrm{pH}$ since supersaturation is reached earlier [30]. After the $\mathrm{pH}$ drop, the rates were proportional to the amount of urease and were slowest for $0.04 \mathrm{U} \mathrm{ml}^{-1}$ urease.

Interestingly, the concentration of free calcium revealed an initial steep decrease immediately after addition of urease, followed by a more gradual decrease at later time points and a second steep decrease after $4 \mathrm{~h}$ due to homogeneous CaP precipitation. The initial steep decrease is likely to point to the formation of pre-nucleation complexes as the equilibrium between dissociated ions and complexes will shift due to the evolving solution $\mathrm{pH}$ [24]. The subsequent gradual decrease can be related to the $\mathrm{pH}$-induced deprotonation of phosphates that capture calcium in newly formed pre-nucleation complexes [24]. As expected, homogeneous precipitation of $\mathrm{CaP}$ resulted a rapid depletion of free calcium followed by a second regime characterized by a continuous decrease in free calcium concentration, the rate of which was higher than the rate of free calcium consumption prior to the onset of homogeneous precipitation, consistent with the growth of a solid, less soluble form of calcium phosphate, i.e the apatite coating.

\subsection{Analysis of CaP formation using cryoTEM}

Recent findings have revealed that the formation of apatite is preceded by the formation and aggregation of solution-based pre-nucleation species consisting of branched ionic polymers of $\mathrm{CaP}$ complexes which are in equilibrium with free ions in solution prior to nucleation of solid CaP crystals in solution [24] or onto templating surfaces [25]. In previous studies dealing with CaP pre-nucleation complexes, a fixed $\mathrm{pH}$ was used as opposed to the changing $\mathrm{pH}$ induced by enzymatic decomposition of urea. In line with the free calcium measurements, cryoTEM imaging confirmed that polymeric assemblies of pre-nucleation complexes were also formed in the current experimental system with variable rather than fixed $\mathrm{pH}$. It was also observed that the final precipitation that was present in the solution after $20 \mathrm{~h}$ was a crystalline, apatitic form of CaP. The subsequent growth and densification of the polymeric structures are in agreement with previous reports that 
A
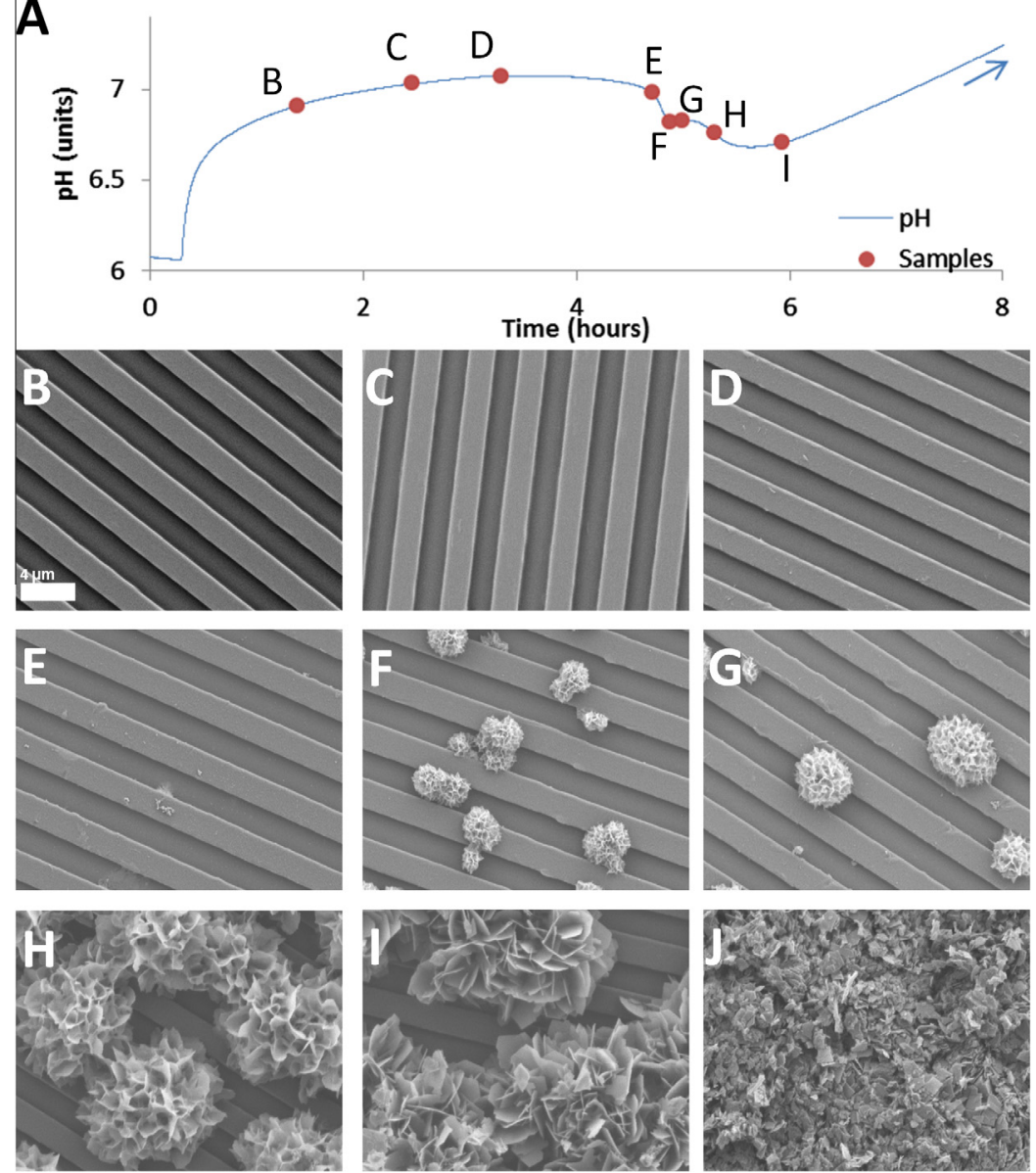

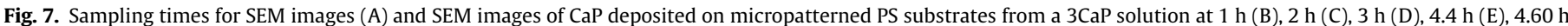

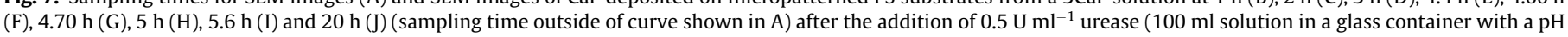
electrode, calcium electrode, temperature sensor and PS substrate present).
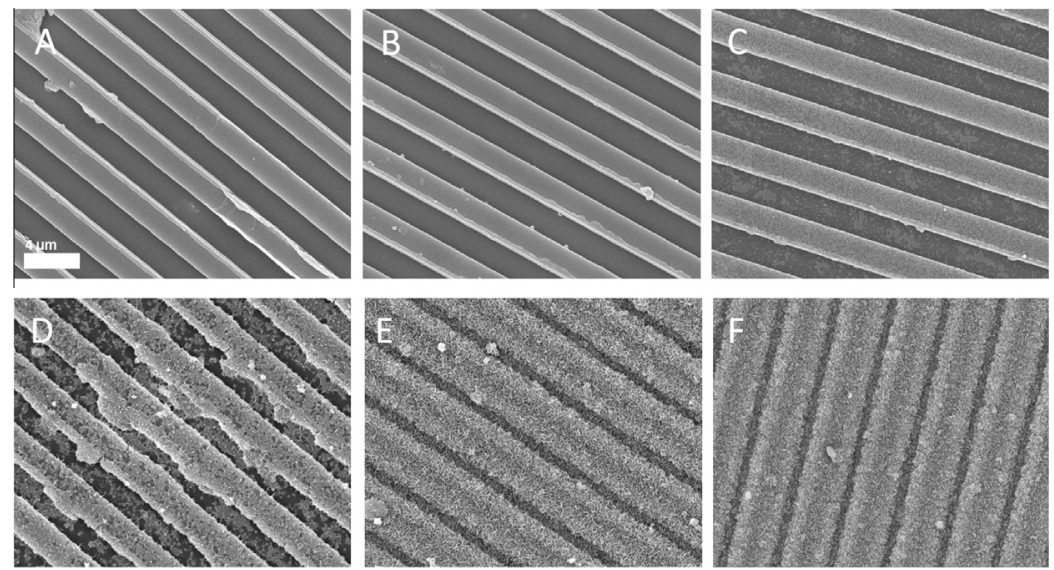

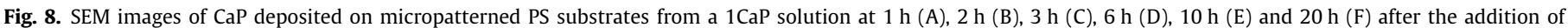
$0.2 \mathrm{U} \mathrm{ml}^{-1}$ urease ( $100 \mathrm{ml}$ solution in a glass container with a pH electrode, temperature sensor and PS substrate present).

the formation of these pre-nucleation species was followed by (i) densification, (ii) formation of amorphous CaP particles, and finally (iii) precipitation of crystalline CaP $[24,25]$. Since these pre-nucleation complexes were present from the very beginning of the experiments, it can be concluded that biomimetic deposition of $\mathrm{CaP}$ coatings is preceded by the formation of ionic polymeric precursors.

\subsection{Analysis of CaP depositions}

The feasibility of enzymatic control of $\mathrm{pH}$ for biomimetic deposition of CaP coatings was confirmed by the successful application of crystalline CaP layers, with characteristics of OCP as well as hydroxyapatite, onto Ti substrates using the substrate-enzyme combination urea-urease. SEM analysis revealed that CaP crystals 

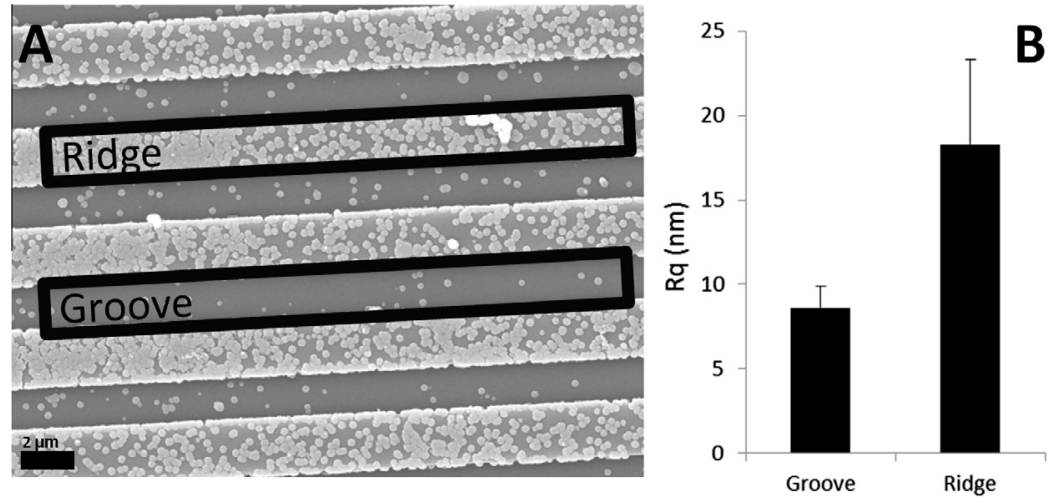

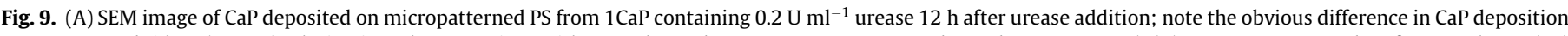

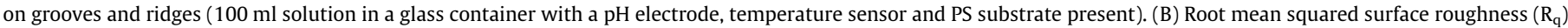
of the groove and ridge of micropatterned PS substrates as measured using AFM (depicted as average \pm standard deviation for $n=14$ ).
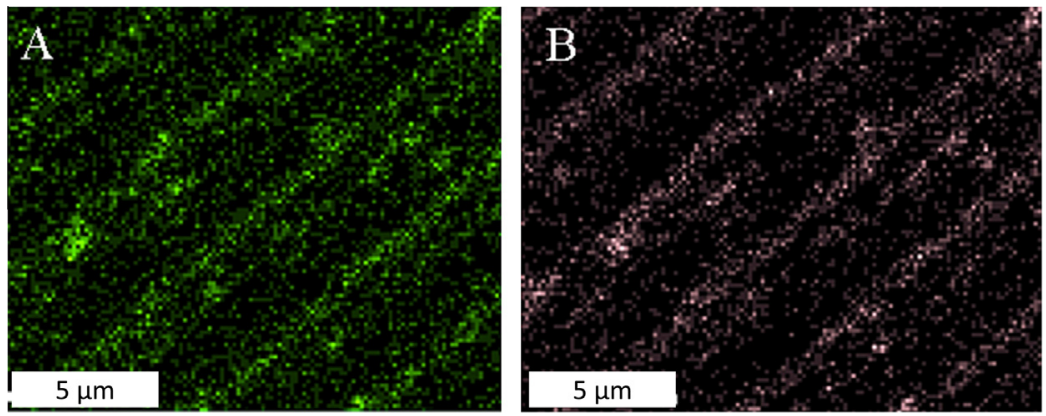

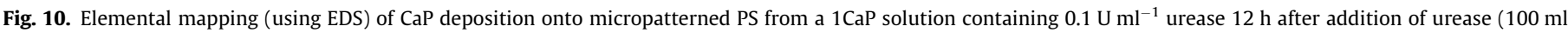
solution in a glass container with a pH electrode, temperature sensor and PS substrate present). Elemental mapping of calcium (A) and phosphorus (B).

nucleated preferentially at the irregularities along the groove edges in concentrated $3 \mathrm{CaP}$ solutions, which grew in size by perpendicular growth away from the substrate surface. In contrast, deposition tended to start from the groove tops for the $1 \mathrm{CaP}$ solution followed by lateral growth of smaller crystals along the substrate surface. Since crystal growth rates generally increase with increasing supersaturation, we speculate that the crystal growth rates were higher in $3 \mathrm{CaP}$ solutions, thereby resulting into homogeneous crystal growth of CaP away from the Ti substrate. Lower crystal growth rates as observed in $1 \mathrm{CaP}$ solutions, on the contrary, induced lateral growth of a higher number of smaller crystals.

The observed spatial differences between the nucleation of $\mathrm{CaP}$ crystals stimulated us to investigate if the process could be optimized for spatially organized deposition of CaP along the edges of micropatterned PS films. Therefore, several experiments were performed at low precursor salt and urease concentrations (ranging from $0.10 .2 \mathrm{U} \mathrm{ml}^{-1}$ urease). Under these conditions, it was possible (Fig. 9A, for 4 out of 12 repetitions of the same experiment) to obtain a unique spatial distribution of CaP along the groove edges of the micropatterned PS substrate by retrieving the samples from the solution after the $\mathrm{pH}$ drop but prior to complete coverage of the entire surface. Elemental mapping using EDS (Fig. 10) confirmed that calcium and phosphorus were accumulated along the groove edges. This spatial distribution of CaP along micropatterned surfaces showed a remarkable similarity to spatial distribution of $\mathrm{CaP}$ in cell culture studies performed by Lamers et al., who observed that osteoblasts deposited CaP along the grooves of nanogrooved PS substrates [31]. We speculate that the higher surface roughness observed on ridges (Fig. 9B) acted as seeds for $\mathrm{CaP}$ deposition, thereby leading to spatial distribution under low concentrations of calcium and phosphate and corresponding rates of crystal nucleation and growth. Nevertheless, it should be emphasized that reproducibility needs to be improved since the degree of spatial distribution of CaP varied between experiments. In addition to the above-mentioned effect of the time-dependent activity of urease, another possible source for the irreproducibility of the (spatial) deposition could be related to the morphology of the nanoroughness resulting from the casting of PS films onto silicon wafer molds. Although quantification of surface nanoroughness in grooves and ridges by AFM indicated that nanoroughness of various PS films were comparable, it cannot be excluded that the morphology of the produced nanoroughness varied between experimental substrates, thereby influencing the kinetics of spatial deposition of $\mathrm{CaP}$.

In general, the relationship between nano/microroughness and (spatial) deposition characteristics is expected to have a strong impact on coating adhesion as well, since it was observed that coatings could only be deposited onto chemically etched $\mathrm{Ti}$ substrates, whereas CaP coatings detached from as-received Ti substrates. In order to be able to prepare strongly adhering coatings in a reproducible manner, future research (performed with standardized experimental conditions and urease activities) on the mechanism of CaP nucleation onto micro- and nanopatterned implant surfaces is therefore necessary.

In summary, the results of the current study indicate that the method presented herein for enzymatic control over pH allows for precise control over supersaturation and corresponding nucleation of $\mathrm{CaP}$, and emphasizes the sensitivity and potential of the substrate-enzyme combination urea-urease for biomimetic deposition of CaP coatings. We anticipate that this system can be 
optimized for preparation of chemically patterned surfaces as well as for simple testing of the calcification ability of a broad range of materials.

\section{Conclusion}

The current study has focused on enzymatic decomposition of urea into carbon dioxide and ammonia as a means to increase the $\mathrm{pH}$ during biomimetic deposition of CaP onto implant surfaces. The data confirm that the substrate-enzyme combination ureaurease offers tight control over the rate of $\mathrm{pH}$ increase in solutions which are metastable with respect to CaP by varying the concentrations of precursor salts and urease. Formation of biomimetic CaP coatings was shown to proceed via formation of ionic polymeric assemblies of prenucleation complexes. The process of nucleation and corresponding coating morphology was strongly dependent on the concentration of calcium, phosphate and urease, resulting in deposition of either micron-sized flake-like CaP crystals vs. nano-sized crystals at low precursor salt concentrations and rate of $\mathrm{pH}$ increase. Finally, it was shown that the substrateenzyme combination urea-urease allowed for spatial distribution of CaP crystals along the grooves of micropatterned PS surfaces at low concentrations of calcium, phosphate and urease, emphasizing the sensitivity of the method described herein.

\section{Acknowledgements}

We are grateful for the financial support from the SmartMix program of the Netherlands Ministry of Economic Affairs and the Netherlands Ministry of Education, Culture and Science (MRN), the Biomedical Materials Bone-IP programme of the Netherlands Ministry of Economic Affairs, Agriculture and Innovation (ZTB) as well as from The Royal Netherlands Academy of Arts and Sciences (KNAW, China-Netherlands Programme Strategic Alliances (PSA) (No. 2008DFB50120)) (A.W.G.N.). J.t.R. is supported by a personal VENI grant (680-47-421) of the Netherlands Organisation for Scientific Research (NWO).

\section{Appendix A. Figures with essential colour discrimination}

Certain figures in this article, particularly Figs. 2, 3, 7 and 10, are difficult to interpret in black and white. The full colour images can be found in the on-line version, at 10.1016/j.actbio.2013.09.036.

\section{References}

[1] Palmer LC, Newcomb CJ, Kaltz SR, Spoerke ED, Stupp SI. Biomimetic systems for hydroxyapatite mineralization inspired by bone and enamel. Chem Rev 2008;108:4754-83.

[2] Kokubo T, Kushitani H, Sakka S, Kitsugi T, Yamamuro T. Solutions able to reproduce in vivo surface-structure changes in bioactive glass-ceramic A-W3. J Biomed Mater Res 1990;24:721-34.

[3] Kokubo T, Takadama H. How useful is SBF in predicting in vivo bone bioactivity? Biomaterials 2006;27:2907-15.

[4] Barrere F, Layrolle P, Van Blitterswijk CA, De Groot K. Biomimetic calcium phosphate coatings on Ti6Al4V: a crystal growth study of octacalcium phosphate and inhibition by $\mathrm{Mg}^{2+}$ and $\mathrm{HCO}_{3}$. Bone 1999;25:107S-11S.
[5] Barrere F, van Blitterswijk CA, de Groot K, Layrolle P. Influence of ionic strength and carbonate on the Ca-P coating formation from $\mathrm{SBF} \times 5$ solution. Biomaterials 2002;23:1921-30.

[6] Barrere F, van Blitterswijk CA, de Groot K, Layrolle P. Nucleation of biomimetic Ca-P coatings on Ti6Al4V from a SBF x 5 solution: influence of magnesium. Biomaterials 2002;23:2211-20.

[7] Deplaine H, Lebourg M, Ripalda P, Vidaurre A, Sanz-Ramos P, Mora G, et al. Biomimetic hydroxyapatite coating on pore walls improves osteointegration of poly(L-lactic acid) scaffolds. J Biomed Mater Res B: Appl Biomater 2013;101B:173-86.

[8] Yu X, Wang L, Jiang X, Rowe D, Wei M. Biomimetic CaP coating incorporated with parathyroid hormone improves the osseointegration of titanium implant. J Mater Sci - Mater Med 2012;23:2177-86.

[9] Hägi TT, Enggist L, Michel D, Ferguson SJ, Liu Y, Hunziker EB. Mechanical insertion properties of calcium-phosphate implant coatings. Clin Oral Implants Res 2010;21:1214-22.

[10] Nijhuis AWG, Leeuwenburgh SCG, Jansen JA. Wet-chemical deposition of functional coatings for bone implantology. Macromol Biosci 2010;10:1316-29.

[11] Elliot JC. Structure and chemistry of the apatites and other calcium orthophophates. Amsterdam: Elsevier; 1994.

[12] Habibovic P, Barrère F, Van Blitterswijk CA, de Groot K, Layrolle P. Biomimetic hydroxyapatite coating on metal implants. J Am Ceram Soc 2002;85:517-22.

[13] Li P. Biomimetic nano-apatite coating capable of promoting bone ingrowth. J Biomed Mater Res 2003;66A:79-85.

[14] Gauckler LJ, Graule T, Baader F. Ceramic forming using enzyme catalyzed reactions. Mater Chem Phys 1999;61:78-102.

[15] Unuma H, Matsushima Y, Kawai T. Enzyme-mediated synthesis of ceramic materials. J Ceram Soc Jpn 2011;119:623-30.

[16] Bayraktar D, Taş AC. Biomimetic preparation of HA powders at $37^{\circ} \mathrm{C}$ in ureaand enzyme urease-containing synthetic body fluids. Turk J Med Sci 2000;30:235-45.

[17] Gutierrez MC, Jobbagy M, Ferrer ML, del Monte F. Enzymatic synthesis of amorphous calcium phosphate-chitosan nanocomposites and their processing into hierarchical structures. Chem Mater 2008;20:11-3.

[18] Jokic B, Tanaskovic D, Jankovic-Castvan I, Drmanic S, Petrovic R, Janackovic D. Synthesis of nanosized calcium hydroxyapatite particles by the catalytic decomposition of urea with urease. J Mater Res 2007;22:1156-61.

[19] Kawai T, Sekikawa H, Unuma H. Preparation of hollow hydroxyapatite microspheres utilizing poly(divinylbenzene) as a template. J Ceram Soc Jpn 2009;117:340-3.

[20] Unuma H, Hiroya M, Ito A. Deposition of bone-like hydroxyapatite on the surface of silk cloth with the aid of immobilized urease. J Mater Sci - Mater Med 2007;18:987-90.

[21] Unuma H, Ito A. Deposition of bone-like apatite layers on the surface of poly(Llactic acid) using immobilized urease. Key Eng Mater 2006;203-311:667-70.

[22] Lamers E, van Horssen R, te Riet J, van Delft FCMJM, Luttge R, Walboomers XF, et al. The influence of nanoscale topographical cues on initial osteoblast morphology and migration. Eur Cell Mater 2010;20:329-43.

[23] Kistiakowsky GB, Rosenberg AJ. The kinetics of urea hydrolysis by urease. JACS 1952;74:5020-5.

[24] Habraken WJEM, Tao J, Brylka LJ, Friedrich H, Bertinetti L, Schenk AS, et al. Ionassociation complexes unite classical and non-classical theories for the biomimetic nucleation of calcium phosphate. Nat Commun 2013;4:1507.

[25] Dey A, Bomans PHH, Müller FA, Will J, Frederik PM, de With G, et al. The role of prenucleation clusters in surface-induced calcium phosphate crystallization. Nat Mater 2010;9:1010-4.

[26] Barrere F, Layrolle P, van Blitterswijk CA, de Groot K. Biomimetic coatings on titanium: a crystal growth study of octacalcium phosphate. J Mater Sci - Mater Med 2001;12:529-34.

[27] Müller FA, Müller L, Caillard D, Conforto E. Preferred growth orientation of biomimetic apatite crystals. J Cryst Growth 2007:304:464-71.

[28] Beniash E, Metzler RA, Lam RSK, Gilbert PUPA. Transient amorphous calcium phosphate in forming enamel. J Struct Biol 2009;166:133-43.

[29] Mahamid J, Aichmayer B, Shimoni E, Ziblat R, Li C, Siegel S, et al. Mapping amorphous calcium phosphate transformation into crystalline mineral from the cell to the bone in zebrafish fin rays. Proc Natl Acad Sci USA 2010;107:6316-21.

[30] Lu X, Leng Y. Theoretical analysis of calcium phosphate precipitation in simulated body fluid. Biomaterials 2005;26:1097-108.

[31] Lamers E, Frank Walboomers X, Domanski M, te Riet J, van Delft FCMJM, Luttge $\mathrm{R}$, et al. The influence of nanoscale grooved substrates on osteoblast behavior and extracellular matrix deposition. Biomaterials 2010;31:3307-16. 